\title{
Platelet-lymphocyte ratio acts as an indicator of poor prognosis in patients with breast cancer
}

\author{
Yanyun Zhu ${ }^{1, *}$, Wen $\mathrm{Si}^{2, *}$, Qiong Sun ${ }^{1}$, Boyu Qin ${ }^{1}$, Weihong Zhao ${ }^{1}$, Junlan Yang ${ }^{1}$ \\ ${ }^{1}$ Department of Medical Oncology, Chinese PLA General Hospital, Beijing 100853, China \\ ${ }^{2}$ Department of Medical Oncology, Beijing Shijitan Hospital, Capital Medical University, Beijing 100038, China \\ *These authors contributed equally to this work \\ Correspondence to: Weihong Zhao, email: zhaowh0818@vip.163.com \\ Junlan Yang, email: yangjunlan301@sina.cn
}

Keywords: breast cancer, prognosis, biomarker, meta-analysis, PLR

Received: August 23, $2016 \quad$ Accepted: November 16, 2016

Published: November 30, 2016

\section{ABSTRACT}

Platelet-lymphocyte ratio (PLR) is a hematological parameter which is investigated as a biomarker for prognosis in patients with breast cancer. Due to the controversial results from previous studies, we performed a meta-analysis. Databases of PubMed, Embase and Web of Science were searched to identify eligible studies. STATA version $\mathbf{1 2 . 0}$ was used for statistical analysis. Seven studies with 3,741 patients were ultimately included in this meta-analysis. High PLR was associated with poor overall survival $(O S)(H R=1.55,95 \% C I=1.07-2.25, p=0.022)$ and disease-free survival (DFS) $(H R=1.73,95 \% C I=1.3-2.3, p<0.001)$ in breast cancer patients. Subgroup analyses disclosed that elevated PLR could predict worse OS in Asian populations and poor DFS in both Asian and non-Asian patients. In addition, PLR remains a significant prognostic marker for OS in patients receiving systemic treatment $(H R=1.78,95 \% C I=1.06-2.99, p=0.03)$ and patients receiving chemotherapy $(\mathrm{HR}=2.82,95 \% \mathrm{CI}=1.09-7.26, p=0.032)$. High PLR also indicates poor DFS in patients who receive chemotherapy $(H R=2.6,95 \% \mathrm{CI}=1.47-4.61$, $p=0.001)$, surgery $(H R=1.8,95 \% C I=1.12-2.89, p=0.016)$ and systemic treatment $(H R=2.03,95 \% C I=1.03-4.01, p=0.042)$. Moreover, PLR was also in association with HER-2 positivity (OR $=1.48,95 \% \mathrm{CI}=1.2-1.83, p<0.001)$. In conclusion, this meta-analysis revealed that PLR could serve as an indicator of poor prognosis in patients with breast cancer.

\section{INTRODUCTION}

Breast cancer is the most commonly diagnosed cancer and the leading cause of cancer mortality in women worldwide [1]. In the past decade, the incidence and mortality of breast cancer is still gradually increasing [2]. Therapeutic approaches including chemotherapy, radiotherapy, and hormonal therapy are applied in clinical practice for breast treatment. However, the long term survival outcomes are still suboptimal, especially for high-risk individuals [3]. Prognostic factors play important roles in risk estimation and treatment responses prediction for cancer patients. For patients with breast cancer, tumor size, lymph node status, histological grade, and hormone receptor status are commonly used prognostic markers. However, the discriminant efficiency of most prognostic biological factors is still lack of accuracy which reflects the fact that easily available and efficient prognostic variables are required.

Recently, inflammatory responses in tumor microenvironment have been shown to be associated with tumor progression and metastases [4]. Cancer-related inflammatory responses and assist cancer cells in the processes of proliferation, infiltration, neovascularization, and dissemination [5]. Some hematological biomarkers are easy available and costless because they are derived from laboratory tests. There parameters include C-reactive protein (CRP), Glasgow Prognostic Score (GPS), plateletlymphocyte ratio (PLR), and neutrophil-lymphocyte ratio (NLR). PLR is calculated as platelet counts divided by lymphocyte counts. PLR is reported to be correlated with worse outcomes in different malignant tumors such as 
colorectal cancer [6], lung cancer [7, 8], and gastric cancer $[9,10]$. Growing evidence also showed that PLR could provide implications for therapeutic modalities selection and prognosis prediction for breast cancer patients [11-13]. However, the association between PLR and breast cancer prognosis is controversial because relevant studies present different results [14-16]. These discrepancies could be caused by different study design and small sample sizes. Therefore, in this study, a meta-analysis was performed to reveal the impact of PLR on survival and clinical characteristics in breast cancer.

\section{RESULTS}

\section{Search results and study characteristics}

Initially, 203 records were identified from electronic databases. After removal of duplicates and inspection of titles and/or abstracts, 18 full-text articles were further evaluated. Of these 18 studies, 11 were excluded because they were studies with inadequate data or did not report data on PLR. As a result, 7 studies [14-20] involving 3,741 patients were enrolled in this study. Detailed search steps were described in Figure 1. The sample sizes vary from 62 to 1,435 per study with a median value of 437 . Five studies [14, 16, 17, 19, 20] were conducted in Asian countries and two studies $[15,18]$ were carried out in nonAsian countries. The cut-off values for PLR ranged from 110 to 292. Six studies [14-19] reported the correlation between PLR and OS and five studies [15-17, 19, 20] investigated the association between PLR and DFS. The NOS scores of all studies were more than 7. General features of the 7 included studies were summarized in Table 1.

\section{Impact of PLR on OS and DFS in breast cancer}

HRs and 95\% CIs from 6 studies [14-19] comprising 3,679 patients were extracted and pooled. Random-effects model was used due to significant heterogeneity $\left(I^{2}=67.3 \%, \mathrm{P}_{\mathrm{h}}=0.009\right.$, Table 2 , Figure $\left.2 \mathrm{~A}\right)$. The pooled results were $\mathrm{HR}=1.55,95 \% \mathrm{CI}=1.072 .25$, $p=0.022$. We also conducted subgroup analysis for further investigation. The results showed that PLR was still an indicator for poor OS in non-Asian patients ( $\mathrm{HR}=2.36$, $95 \% \mathrm{CI}=1.58-3.52, p<0.001)$ and in studies with sample

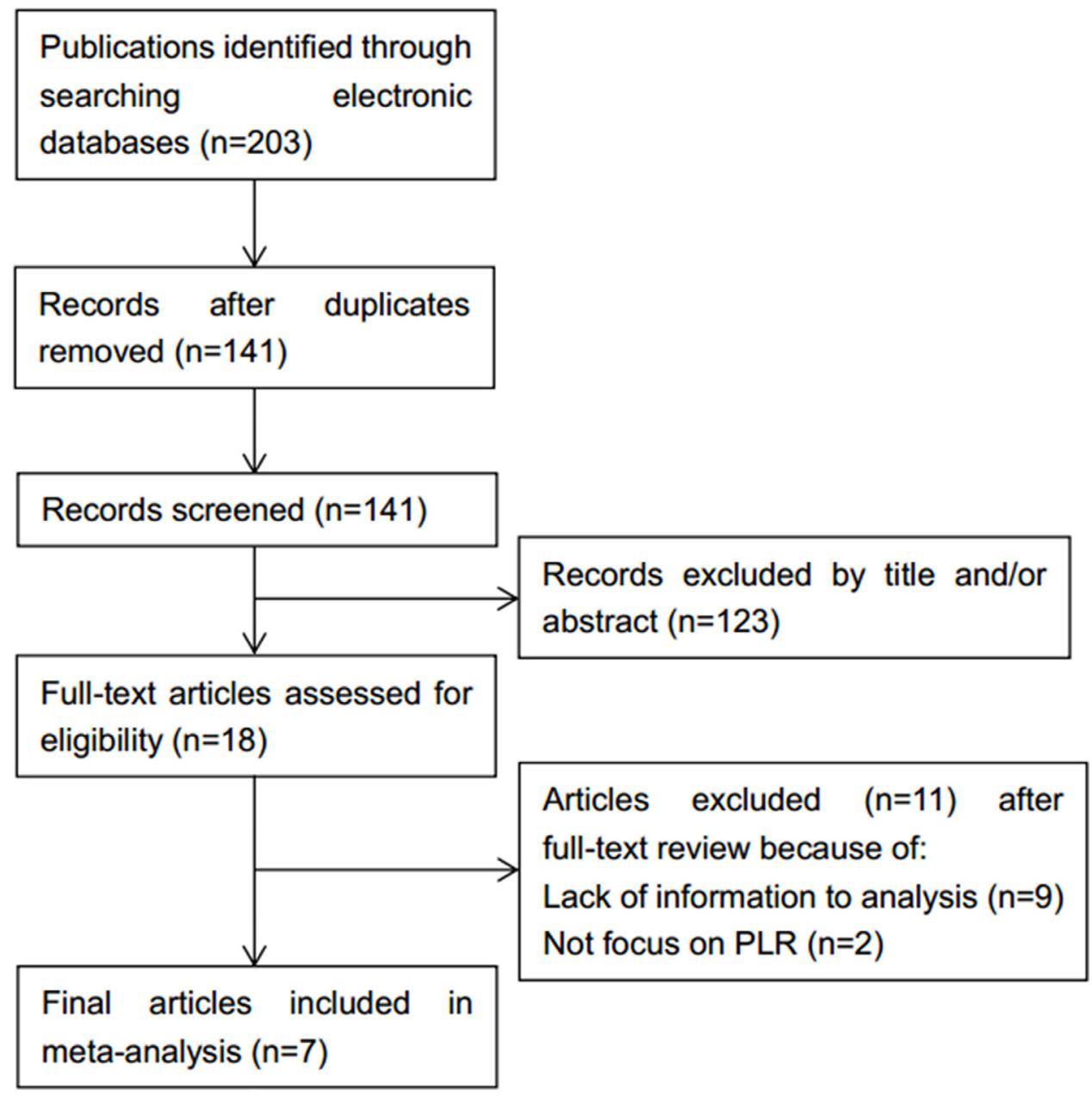

Figure 1: Methodological flow diagram of the meta-analysis. 
Table 1: Main characteristics of included studies in meta-analysis

\begin{tabular}{l|c|l|c|c|c|l|c|c|l|c|}
\hline \multicolumn{1}{c}{ Study } & \multicolumn{2}{c}{ Year } & \multicolumn{2}{c}{ Region } & \multicolumn{1}{c}{$\begin{array}{c}\text { Sample } \\
\text { size }\end{array}$} & \multicolumn{2}{c}{$\begin{array}{c}\text { Research } \\
\text { period }\end{array}$} & \multicolumn{2}{c}{ Stage } & \multicolumn{2}{c}{ Treatment } & \multicolumn{2}{c}{$\begin{array}{c}\text { Cut-off } \\
\text { value }\end{array}$} & Outcome & $\begin{array}{c}\text { NOS } \\
\text { score }\end{array}$ \\
\hline Asano & 2016 & Japan & 177 & $2007-2013$ & II -IV & Chemotherapy & 150 & OS, DFS & 8 \\
\hline Azab & 2013 & USA & 437 & $2004-2006$ & I -IV & Systemic treatment & 185 & OS & 7 \\
\hline Cihan & 2014 & Turkey & 350 & $2005-2010$ & I -III & Radiotherapy & 160 & OS, DFS & 8 \\
\hline Gunduz & 2015 & Turkey & 62 & $2008-2010$ & I -III & Chemotherapy & 200 & DFS & 8 \\
\hline Hong & 2016 & China & 487 & $2009-2010$ & I -III & Surgery & 110 & OS, DFS & 8 \\
\hline Koh & 2015 & Malaysia & 1435 & $2000-2008$ & I -IV & Systemic treatment & 185 & OS & 7 \\
\hline Krenn-Pilko & 2014 & Austria & 793 & $1999-2004$ & I -III & Systemic treatment & 292 & OS, DFS & 8 \\
\hline
\end{tabular}

sizes $>400(\mathrm{HR}=1.67,95 \% \mathrm{CI}=1.13-2.47, p=0.01)$. In addition, PLR remains a significant prognostic marker for OS in patients receiving systemic treatment $(\mathrm{HR}=1.78,95 \% \mathrm{CI}=1.06-2.99, p=0.03)$ and patients receiving chemotherapy $(\mathrm{HR}=2.82,95 \% \mathrm{CI}=1.09-7.26$, $p=0.032)$. A total of 5 studies $[15-17,19,20]$ containing
1,869 patients reported the prognostic significance of PLR on DFS. The pooled results showed that PLR was significantly associated with worse DFS (HR $=1.73$, $95 \% \mathrm{CI}=1.3-2.3, p<0.001)$ and the heterogeneity was not significant $\left(I^{2}=40.5 \%, P_{\mathrm{h}}=0.151\right.$, Table 2 , Figure 2B). Subgroup analysis demonstrated that PLR was

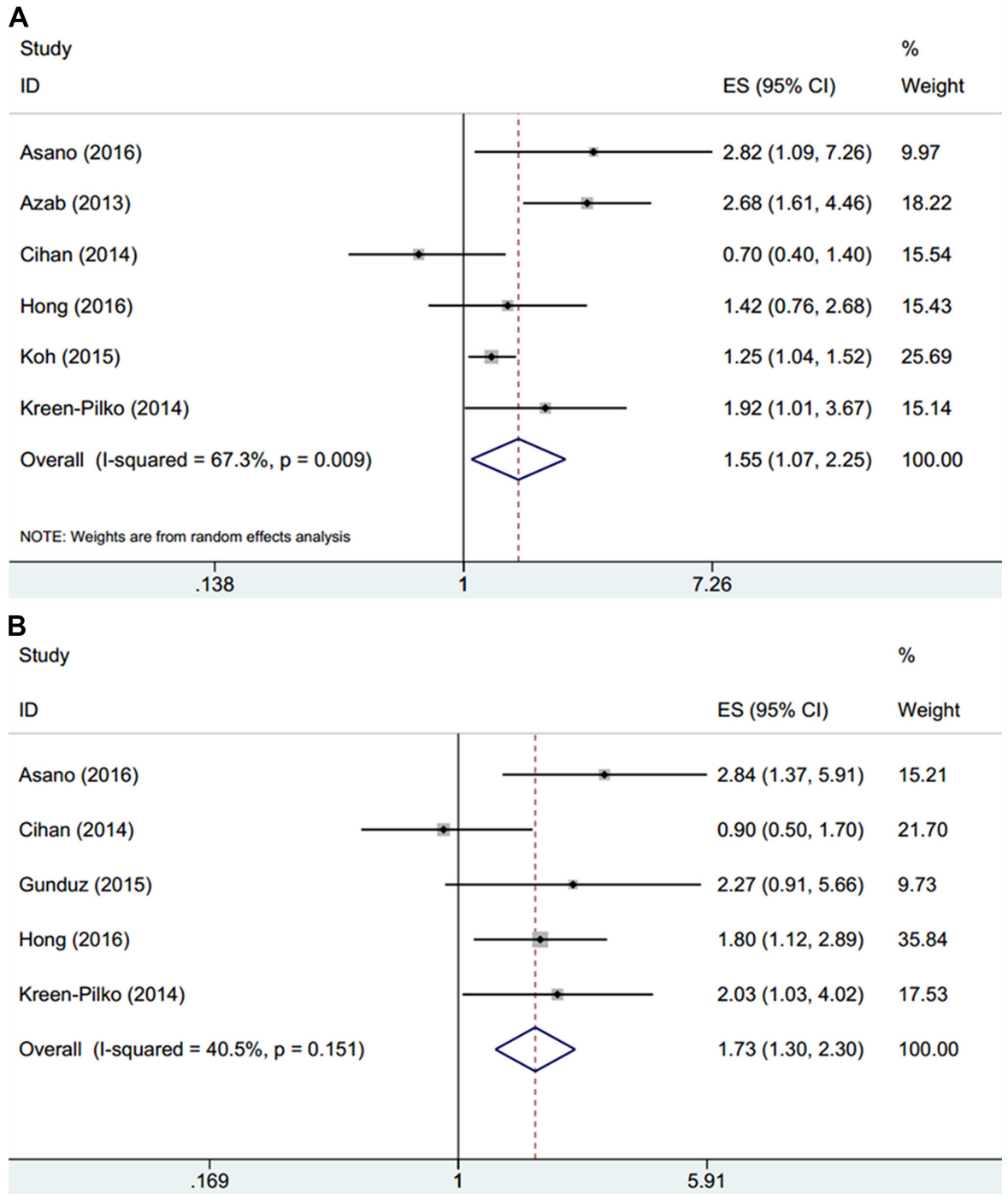

Figure 2: Forrest plots of studies evaluating HRs of the PLR for (A) OS and (B) DFS. 
Table 2: Meta-analysis of PLR and OS, DFS

\begin{tabular}{|c|c|c|c|c|c|c|c|}
\hline \multirow{2}{*}{ Factors } & \multirow{2}{*}{$\begin{array}{l}\text { No. of } \\
\text { studies }\end{array}$} & \multirow{2}{*}{$\begin{array}{c}\text { No. of } \\
\text { patients }\end{array}$} & \multirow{2}{*}{ HR (95\% CI) } & \multirow[b]{2}{*}{$p$} & \multirow{2}{*}{$\begin{array}{l}\text { Effects } \\
\text { model }\end{array}$} & \multicolumn{2}{|c|}{ Heterogeneity } \\
\hline & & & & & & $I^{2}(\%)$ & $P_{\mathrm{h}}$ \\
\hline Overall for OS & 6 & 3,679 & $1.55(1.07-2.25)$ & 0.022 & Random & 67.3 & 0.009 \\
\hline \multicolumn{8}{|l|}{ Region } \\
\hline Asian & 4 & 2,449 & $1.26(0.85-1.85)$ & 0.251 & Random & 52.2 & 0.099 \\
\hline Non-Asian & 2 & 1,230 & $2.36(1.58-3.52)$ & $<0.001$ & Fixed & 0 & 0.427 \\
\hline \multicolumn{8}{|l|}{ Treatment } \\
\hline Systemic treatment & 3 & 2,665 & $1.78(1.06-2.99)$ & 0.03 & Random & 76.6 & 0.014 \\
\hline Chemotherapy & 1 & 177 & $2.82(1.09-7.26)$ & 0.032 & - & - & - \\
\hline Radiotherapy & 1 & 350 & $0.7(0.37-1.31)$ & 0.264 & - & - & - \\
\hline Surgery & 1 & 487 & $1.42(0.76-2.68)$ & 0.273 & - & - & - \\
\hline \multicolumn{8}{|l|}{ Sample size $(n)$} \\
\hline$>400$ & 4 & 3,152 & $1.67(1.13-2.47)$ & 0.01 & Random & 64.8 & 0.036 \\
\hline$<400$ & 2 & 527 & $1.34(0.34-5.23)$ & 0.674 & Random & 82.7 & 0.016 \\
\hline Overall for DFS & 5 & 1,869 & $1.73(1.3-2.3)$ & $<0.001$ & Fixed & 40.5 & 0.151 \\
\hline \multicolumn{8}{|l|}{ Region } \\
\hline Asian & 4 & 1,076 & $1.72(1.06-2.8)$ & 0.027 & Random & 53.6 & 0.091 \\
\hline Non-Asian & 1 & 793 & $2.03(1.03-4.01)$ & 0.042 & - & - & - \\
\hline \multicolumn{8}{|l|}{ Treatment } \\
\hline Chemotherapy & 2 & 239 & $2.6(1.47-4.61)$ & 0.001 & Fixed & 0 & 0.708 \\
\hline Radiotherapy & 1 & 350 & $0.9(0.49-1.66)$ & 0.736 & - & - & - \\
\hline Surgery & 1 & 487 & $1.8(1.12-2.89)$ & 0.016 & - & - & - \\
\hline Systemic treatment & 1 & 793 & $2.03(1.03-4.01)$ & 0.042 & - & - & - \\
\hline \multicolumn{8}{|l|}{ Sample size $(n)$} \\
\hline$>400$ & 2 & 1,280 & $1.87(1.27-2.76)$ & 0.002 & Fixed & 0 & 0.773 \\
\hline$<400$ & 3 & 589 & $1.73(0.81-3.72)$ & 0.158 & Random & 68.4 & 0.042 \\
\hline
\end{tabular}

$\mathrm{OS}=$ overall survival; $\mathrm{DFS}=$ disease-free survival.

connected with shorter DFS in both Asian patients (HR $=1.72,95 \% \mathrm{CI}=1.06-2.8, p=0.027)$ and non-Asian countries $(\mathrm{HR}=2.03,95 \% \mathrm{CI}=1.03-4.01, p=0.042)$ and in studies with patients amount $>400(\mathrm{HR}=1.87$, $95 \% \mathrm{CI}=1.27-2.76, p=0.002$ ). Moreover, high PLR also indicates poor DFS in patients who receive chemotherapy $(\mathrm{HR}=2.6,95 \% \mathrm{CI}=1.47-4.61, p=0.001)$, surgery $(\mathrm{HR}=1.8,95 \% \mathrm{CI}=1.12-2.89, p=0.016)$ and systemic treatment $(\mathrm{HR}=2.03,95 \% \mathrm{CI}=1.03-4.01, p=0.042)$. These results indicated that high PLR was significantly associated with poor OS and DFS in patients with breast cancer.

\section{Relationships between PLR and clinicopathological features}

We explored the correlation between PLR and 6 clinicopathological parameters. As shown in Figure 3, PLR was shown to be associated with human epidermal growth factor receptor-2 (HER-2) positivity $(\mathrm{OR}=1.48$, $95 \% \mathrm{CI}=1.2-1.83, p<0.001)$. However, the pooled data demonstrated that PLR was not significantly correlated with other 5 clinicopathological factors including lymph node metastasis $(\mathrm{OR}=1.23,95 \% \mathrm{CI}=0.88-1.73$, $p=0.229)$, unclear grade $(\mathrm{OR}=0.94,95 \% \mathrm{CI}=0.48-1.84$, $p=0.859)$, estrogen receptor (ER) status ( $\mathrm{OR}=0.93,95 \%$ $\mathrm{CI}=0.78-1.11, p=0.42)$, progesterone receptor $(\mathrm{PR})$ status $(\mathrm{OR}=0.88,95 \% \mathrm{CI}=0.73-1.06, p=0.168)$ or AJCC stage $(\mathrm{OR}=1.51,95 \% \mathrm{CI}=0.85-2.67, p=0.158)$.

\section{Publication bias}

We performed Begg's funnel plot and Egger's linear regression test to estimate potential publication bias in this meta-analysis. The $p$ values for OS were 0.452 (Begg's test) and 0.418 (Egger's test) and $p$ values for DFS were 0.221 (Begg's test) and 0.583 (Egger's test). The results showed that there was no significant publication bias in our study. 


\section{DISCUSSION}

In this meta-analysis containing 7 studies, the combined results showed that PLR was a significant biomarker for poor OS $(\mathrm{HR}=1.55,95 \% \mathrm{CI}=1.07-2.25$, $p=0.022)$ and DFS $(\mathrm{HR}=1.73,95 \% \mathrm{CI}=1.3-2.3$, $p<0.001)$. Subgroup analyses disclosed that elevated PLR could predict worse OS in Asian populations and poor DFS in both Asian and non-Asian patients. In addition, PLR was also in association with HER-2 positivity $(\mathrm{OR}=1.48,95 \% \mathrm{CI}=1.2-1.83, p<0.001)$. Taken all these into consideration, PLR could serve as a convenient and reliable marker for breast cancer prognostication.

Tumor-promoting inflammation is an emerging hallmark of cancer [21]. Systemic inflammatory responses can facilitate tumor progression in almost every single step including initiation, progression, and metastasis [5]. On the one hand, current evidence shows that platelets can guard tumor cells from immune elimination and are involved in development of aggressive tumor behaviors [22]. In addition, platelets can promote tumor-cell transendothelial migration and metastasis through the mediation of $\mathrm{P} 2 \mathrm{Y}_{2}$ receptor [23]. Platelets can secret a variety of growth factors including platelet derived growth factor (PDGF) [24], platelet-activating factor (PAF) [25], and vascular endothelium growth factor (VEGF) [26], which could further support tumor growth, angiogenesis and metastasis [27]. Therefore, increased platelet counts have negative effects on patient survival. On the other hand, lymphocytes play an important role in tumor-derived inflammatory responses [28]. Lymphocytes have an antitumor activity by inducing cytotoxic cell death and inhibiting tumor proliferation [4]. Several studies reported that the increased infiltration of lymphocytes in tumor tissue predicted better survival outcomes in cancer patients [29, 30].

Notably, previous studies showed that high PLR was in association with poor survival in other tumors including non-small cell lung cancer [31], colorectal cancer [32], gastric cancer [33], and various solid tumors [34, 35] by performing meta-analysis. Our results regarding breast

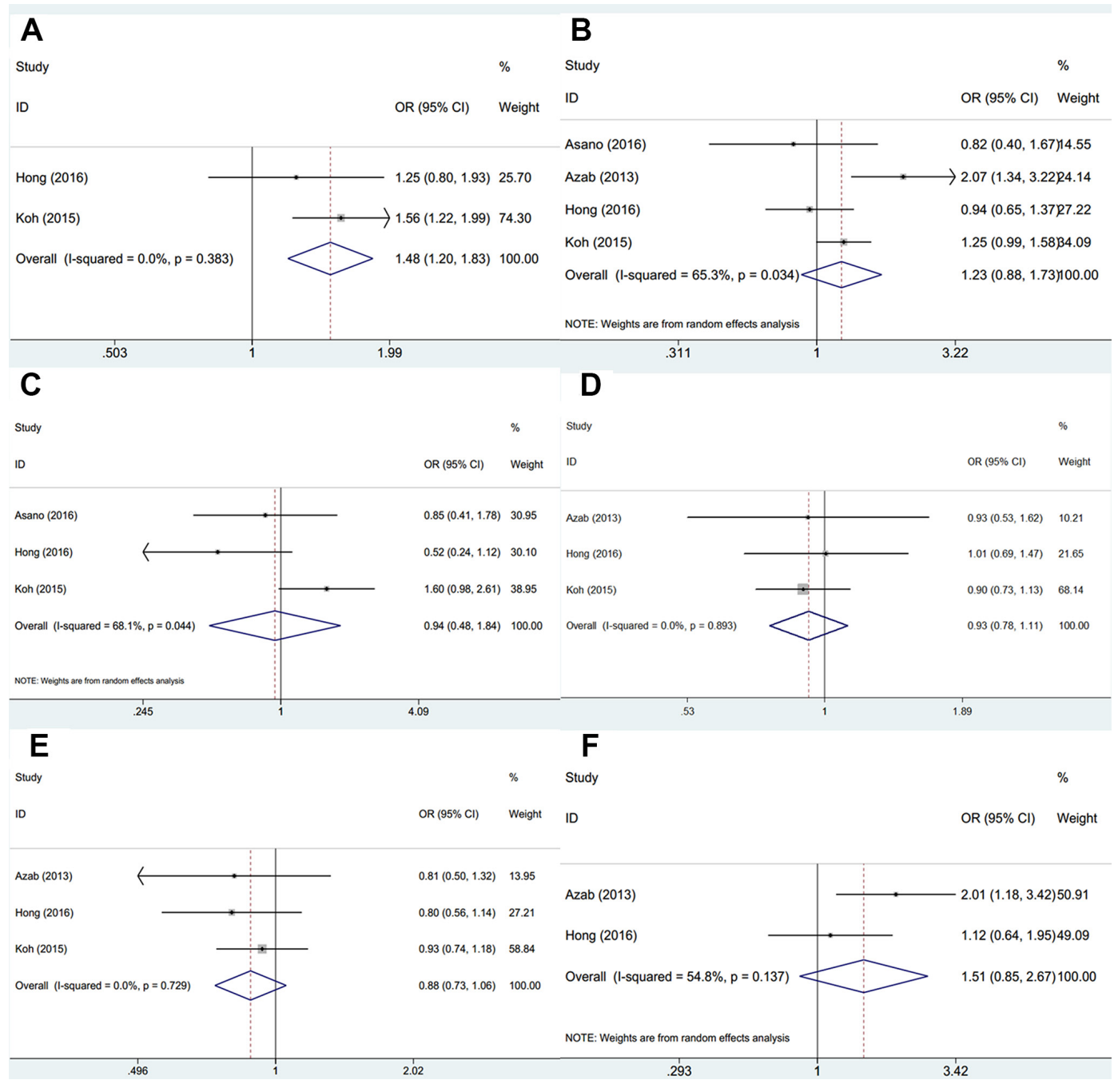

Figure 3: Forrest plots of associations between PLR and (A) HER-2 status; (B) Lymph node metastasis; (C) Unclear grade; (D) ER status; (E) PR status and (F) AJCC stage. 
cancer were in line with results of studies on other cancer forms [31, 33, 36]. We noted that breast cancer was investigated merely as a small proportion of all cancer types in previous meta-analyses with at most two primary studies included $[34,35]$. There was no study focusing on the prognostic value of PLR on breast cancer through meta-analysis. To our knowledge, the present study is the first meta-analysis to investigate the relationship between PLR and breast cancer.

There are several limitations to our study. First, this meta-analysis was performed based on the pooled HRs and 95\% CIs from eligible studies other than detailed individual information. Thus, potential bias may still exist. Second, the cut-off values for PLR were different in included studies, because they identified the cut-off values according to various criteria. Although the patient groups were divided into PLR-high and PLR-low populations, the stratifications may change when the cut-off changes. Therefore, a standard and uniform cut-off value defining high PLR is needed.

In conclusion, this meta-analysis demonstrated that high PLR was an indicator of worse OS and DFS in breast cancer. Moreover, PLR was related to HER-2 positivity. Further high-quality and large-scale studies are required to determine the validation of other results.

\section{MATERIALS AND METHODS}

\section{Search strategy}

This study was conducted referring to the Preferred Reporting Items for Systematic Reviews and MetaAnalyses (PRISMA) statement [37]. Relevant studies were thoroughly searched from PubMed, Embase, Web of Science, and China National Knowledge Infrastructure (CNKI) up to August, 2016. The search strategy included following keywords: "PLR", "platelet lymphocyte ratio", "breast cancer", "breast carcinoma", and "breast neoplasms" [MeSH Terms]. References in all relevant articles were also checked to identify potentially relevant studies. There was no language restriction.

\section{Selection criteria}

Inclusion criteria were as follows: (1) PLR was measured pretreatment on basis of blood tests; (2) the diagnosis of breast cancer established by pathological examination; (3) reported a cut-off value for PLR; (4) reported the associations between PLR and survival outcomes; (5) sufficient data were provided to calculate hazard ratios (HRs) and 95\% confidence intervals (CIs). Exclusion criteria in this study were as follows: (1) reviews, case reports, conference abstracts and letters; (2) studies with insufficient data; (3) animal studies. Two independent investigators (YYZ and WS) evaluated the candidate studies and disagreements were resolved by discussing with a third investigator (JLY).

\section{Data extraction and quality assessment}

Two investigators (YYZ and WS) independently performed the data extraction from eligible studies. The following information was extracted: first author's name, year of publication, country, sample size, research period, survival outcomes, cut-off value, and clinicalpathological characteristics. The qualities of included studies were evaluated using Newcastle-Ottawa Quality Scale (NOS) assessment [38]. Three parts including selection, comparability, and outcomes were evaluated in this scale with a maximum score of 9 . Studies with scores $\geq 7$ were considered as high-quality studies.

\section{Statistical analysis}

HR and 95\% CI were used as the effective measures to estimate the relationships of PLR and overall survival (OS) and disease-free survival (DFS). If possible, HRs and $95 \%$ CIs were directly extracted from included studies, or they were computed based on methods by Tierney et al [39]. Odds ratio (OR) and 95\% CI were utilized to evaluate the associations between PLR and clinicopathological factors. Heterogeneity among studies was assessed by Cochran's $Q$ test and the Higgins' $I^{2}$ statistic. A $P$ value for heterogeneity $<0.05$ and/ or $I^{2}>50 \%$ indicated significant heterogeneity, and a random-effects model was used; otherwise, a fixed-effects model was applied. Publication bias was tested by Begg's funnel plots and Egger's linear regression test. $P<0.05$ was considered as statistically significant. All analyses were performed by using STATA version 12.0 (Stata Corporation, College Station, TX, USA).

\section{ACKNOWLEDGMENTS AND GRANT SUPPORT}

This work was supported by Wu Jieping Medical Foundation (No. 320.6750.14331)

\section{CONFLICTS OF INTEREST}

The authors have no conflict of interests in work described in this manuscript.

\section{REFERENCES}

1. Torre LA, Bray F, Siegel RL, Ferlay J, Lortet-Tieulent J, Jemal A. Global Cancer Statistics, 2012. Cancer J Clin. 2015; 65:87-108.

2. DeSantis C, Siegel R, Bandi P, Jemal A. Breast cancer statistics, 2011. Cancer J Clin. 2011; 61:409-418. 
3. Assi HA, Khoury KE, Dbouk H, Khalil LE, Mouhieddine TH, El Saghir NS. Epidemiology and prognosis of breast cancer in young women. J Thorac Dis. 2013; 5:S2-8.

4. Mantovani A, Allavena P, Sica A, Balkwill F. Cancer-related inflammation. Nature. 2008; 454:436-444.

5. Coussens LM, Werb Z. Inflammation and cancer. Nature. 2002; 420:860-867.

6. Kwon HC, Kim SH, Oh SY, Lee S, Lee JH, Choi HJ, Park KJ, Roh MS, Kim SG, Kim HJ, Lee JH. Clinical significance of preoperative neutrophil-lymphocyte versus platelet-lymphocyte ratio in patients with operable colorectal cancer. Biomarkers. 2012; 17:216-222.

7. Hong X, Cui B, Wang M, Yang Z, Wang L, Xu Q. Systemic Immune-inflammation Index, Based on Platelet Counts and Neutrophil-Lymphocyte Ratio, Is Useful for Predicting Prognosis in Small Cell Lung Cancer. Tohoku J Exp Med. $2015 ; 236: 297-304$.

8. Zhang H, Xia H, Zhang L, Zhang B, Yue D, Wang C. Clinical significance of preoperative neutrophil-lymphocyte vs platelet-lymphocyte ratio in primary operable patients with non-small cell lung cancer. Am J Surg. 2015; 210:526-535.

9. Gunaldi M, Goksu S, Erdem D, Gunduz S, Okuturlar Y, Tiken E, Kahraman S, Inan YO, Genc TB, Yildirim M. Prognostic impact of platelet/lymphocyte and neutrophil/ lymphocyte ratios in patients with gastric cancer: a multicenter study. Int J Clin Exp Med. 2015; 8:5937-5942.

10. Sun KY, Xu JB, Chen SL, Yuan YJ, Wu H, Peng JJ, Chen CQ, Guo P, Hao YT, He YL. Novel immunological and nutritional-based prognostic index for gastric cancer. World J Gastroenterol. 2015; 21:5961-5971.

11. Okuturlar Y, Gunaldi M, Tiken EE, Oztosun B, Inan YO, Ercan T, Tuna S, Kaya AO, Harmankaya O, Kumbasar A. Utility of peripheral blood parameters in predicting breast cancer risk. Asian Pac J Cancer Prev. 2015; 16:2409-2412.

12. Seretis C, Seretis F, Lagoudianakis E, Politou M, Gemenetzis G, Salemis NS. Enhancing the accuracy of platelet to lymphocyte ratio after adjustment for large platelet count: a pilot study in breast cancer patients. Int $\mathrm{J}$ Surg Oncol. 2012; 2012:653608.

13. Ulas A, Avci N, Kos T, Cubukcu E, Olmez OF, Bulut N, Degirmenci M. Are neutrophil/lymphocyte ratio and platelet/lymphocyte ratio associated with prognosis in patients with HER2-positive early breast cancer receiving adjuvant trastuzumab? J BUON. 2015; 20:714-722.

14. Koh CH, Bhoo-Pathy N, Ng KL, Jabir RS, Tan GH, See MH, Jamaris S, Taib NA. Utility of pre-treatment neutrophil-lymphocyte ratio and platelet-lymphocyte ratio as prognostic factors in breast cancer. Br J Cancer. 2015; 113:150-158.

15. Krenn-Pilko S, Langsenlehner U, Thurner EM, Stojakovic T, Pichler M, Gerger A, Kapp KS, Langsenlehner T. The elevated preoperative platelet-to-lymphocyte ratio predicts poor prognosis in breast cancer patients. Br J Cancer. 2014; 110:2524-2530.
16. Hong J, Mao Y, Chen XS, He JR, Zhu L, Chen WG, Li YF, Fei XC, Lin L, Shen KW. Significance of platelet and lymphocyte counts for predicting the prognosis of patients with breast cancer. Journal of Shanghai Jiaotong University (Medical Science). 2016; 36:369-374.

17. Asano Y, Kashiwagi S, Onoda N, Noda S, Kawajiri H, Takashima T, Ohsawa M, Kitagawa S, Hirakawa K. Platelet-Lymphocyte Ratio as a Useful Predictor of the Therapeutic Effect of Neoadjuvant Chemotherapy in Breast Cancer. PLoS One. 2016; 11:e0153459.

18. Azab B, Shah N, Radbel J, Tan P, Bhatt V, Vonfrolio S, Habeshy A, Picon A, Bloom S. Pretreatment neutrophil/ lymphocyte ratio is superior to platelet/lymphocyte ratio as a predictor of long-term mortality in breast cancer patients. Med Oncol. 2013; 30.

19. Cihan YB, Arslan A, Cetindag MF, Mutlu H. Lack of Prognostic Value of Blood Parameters in Patients Receiving Adjuvant Radiotherapy for Breast Cancer. Asian Pac J Cancer Prev. 2014; 15:4225-4231.

20. Gunduz S, Goksu SS, Arslan D, Tatli AM, Uysal M, Gunduz UR, Sevinc MM, Coskun HS, Bozcuk H, Mutlu H, Savas B. Factors affecting disease-free survival in patients with human epidermal growth factor receptor 2-positive breast cancer who receive adjuvant trastuzumab. Mol Clin Oncol. 2015; 3:1109-1112.

21. Hanahan D, Weinberg RA. Hallmarks of Cancer: The Next Generation. Cell. 2011; 144:646-674.

22. Gay LJ, Felding-Habermann B. Contribution of platelets to tumour metastasis. Nat Rev Cancer. 2011; 11:123-134.

23. Schumacher D, Strilic B, Sivaraj KK, Wettschureck N, Offermanns S. Platelet-derived nucleotides promote tumorcell transendothelial migration and metastasis via P2Y2 receptor. Cancer Cell. 2013; 24:130-137.

24. Ariad S, Seymour L, Bezwoda WR. Platelet-derived growth factor (PDGF) in plasma of breast cancer patients: correlation with stage and rate of progression. Breast Cancer Res Treat. 1991; 20:11-17.

25. van den Bosch $\mathrm{H}$, de Vet EC, Zomer AW. The role of peroxisomes in ether lipid synthesis. Back to the roots of PAF. Adv Exp Med Biol. 1996; 416:33-40.

26. Sullivan LA, Brekken RA. The VEGF family in cancer and antibody-based strategies for their inhibition. MAbs. 2010; 2:165-175.

27. Goubran HA, Burnouf T, Radosevic M, El-Ekiaby M. The platelet-cancer loop. Eur J Intern Med. 2013; 24:393-400.

28. Smyth MJ, Dunn GP, Schreiber RD. Cancer immunosurveillance and immunoediting: the roles of immunity in suppressing tumor development and shaping tumor immunogenicity. Adv Immunol. 2006; 90:1-50.

29. Nguyen N, Bellile E, Thomas D, McHugh J, Rozek L, Virani S, Peterson L, Carey TE, Walline H, Moyer J, Spector M, Perim D, Prince M, et al. Tumor infiltrating lymphocytes and survival in patients with head and neck squamous cell carcinoma. Head Neck. 2016; 38:1074-1084. 
30. Mao Y, Qu Q, Chen XS, Huang O, Wu JY, Shen KW. The Prognostic Value of Tumor-Infiltrating Lymphocytes in Breast Cancer: A Systematic Review and Meta-Analysis. PLoS One. 2016; 11:13.

31. Zhao QT, Yuan Z, Zhang H, Zhang XP, Wang HE, Wang ZK, Duan GC. Prognostic role of platelet to lymphocyte ratio in non-small cell lung cancers: A meta-analysis including 3,720 patients. Int J Cancer. 2016; 139:164-170.

32. Tan D, Fu Y, Su Q, Wang H. Prognostic role of plateletlymphocyte ratio in colorectal cancer: A systematic review and meta-analysis. Medicine (Baltimore). 2016; 95:e3837.

33. Gu X, Gao XS, Cui M, Xie M, Peng C, Bai Y, Guo W, Han L, Gu X, Xiong W. Clinicopathological and prognostic significance of platelet to lymphocyte ratio in patients with gastric cancer. Oncotarget. 2016; 7:49878-49887. doi: 10.18632/oncotarget.10490.

34. Templeton AJ, Ace O, McNamara MG, Al-Mubarak M, Vera-Badillo FE, Hermanns T, Seruga B, Ocana A, Tannock IF, Amir E. Prognostic role of platelet to lymphocyte ratio in solid tumors: a systematic review and meta-analysis. Cancer Epidemiol Biomarkers Prev. 2014; 23:1204-1212.

35. Zhou X, Du YP, Huang ZB, Xu J, Qiu TZ, Wang J, Wang TS, Zhu W, Liu P. Prognostic Value of PLR in Various Cancers: A Meta-Analysis. PLoS One. 2014; 9.

36. Zhang H, Gao L, Zhang B, Zhang L, Wang C. Prognostic value of platelet to lymphocyte ratio in non-small cell lung cancer: a systematic review and meta-analysis. Sci Rep. 2016; 6:22618.

37. Moher D, Liberati A, Tetzlaff J, Altman DG. Preferred reporting items for systematic reviews and meta-analyses: the PRISMA statement. PLoS Med. 2009; 6:e1000097.

38. Stang A. Critical evaluation of the Newcastle-Ottawa scale for the assessment of the quality of nonrandomized studies in meta-analyses. Eur J Epidemiol. 2010; 25:603-605.

39. Tierney JF, Stewart LA, Ghersi D, Burdett S and Sydes MR. Practical methods for incorporating summary time-to-event data into meta-analysis. Trials. 2007; 8:16. 